\title{
A New Segmentation Method for Rotational Landslide Detection Using Outlier Detection
}

\author{
Cahit Tagi CELIK
}

\begin{abstract}
A new segmentation method for detection of rotational landslides from two epochs of Light Detection and Ranging System data (LiDAR) was developed. The developed method is based on outlier detection using Z scores of standard normal distribution. In this method, outlying height differences were obtained from two epochs of LiDAR data. The height differences were determined for each ith point uniquely by gridding the area along the steepest slope direction. Then, each profile containing the outlying height differences was tested for conformity to a possible rotational landslide and grouped into horizontal sets. Finally, the procedure was applied to horizontally grouped sets in the direction perpendicular to the steepest slope to determine each rotational landslide. To test the developed method, the area containing five different sizes of rotational landslides was scanned by the developed method. The results showed that the developed method segmented the area successfully identifying each rotational landslide.
\end{abstract}

Keywords: Landslide Detection; LiDAR; Rotational Landslide; Segmentation

\section{INTRODUCTION}

Over the last decade, Light Detection And Ranging System (LiDAR) data has been used for acquiring accurate three dimensional coordinates including the intensities of the returned signals; therefore, it is used for variety of applications including geodesy [1]. Landslide detection has a close relationship with geodesy since landslides are simply surface deformations. Understanding landslides and their mechanism may contribute to preventing its hazards. Therefore, landslide detection and determination of its parameters are important. Several researchers used LiDAR based high resolution DTM for landslide detections. A study showed that local surface roughness can be accurately determined from high resolution DEM based on LiDAR with the aim of deriving information about special extent, internal kinematics and relative activity of bedrock landslides [2].The author in [3] demonstrated the local topography variability for landform mapping and characterization of two landslide in Southern Idaho using LiDAR data. A study was carried out to detect landslides features using remote sensing techniques in rock masses at the Betic Cordilleras, Spain [4]. The authors in [5] studied landslide detection bigger than $0.5 \mathrm{~m}$ using multi-temporal two epochs of LiDAR data along with supplemental optical satellite imagery (QuickBird). A broad review of landslide studies was done by [6]. The authors in [7] studied automatic recognition of landslide crowns and features related to bank erosion of channels. A better insight into airborne laser scanning data (ALS) was provided by [8]. The authors in [9] proposed a landslide detection procedure in forested area using aspect, digital terrain model (DTM) and slope images. The author in [10] reviewed studies concerning analysis of surface morphology, which included mass movements, hill slopeto-valley transition morphology, identification of channel network extraction, river morphology analysis, bank erosion analysis etc. The authors in [11] studied weightsof-evidence (WofE) landslide susceptibility model in areas that are very different in terms of size, geo-environmental settings, and landslide types. However, majority of the studies done in this field used one set of LiDAR data for producing high resolution DEM, used image based landslide detection, and did not focus on a particular type of landslides.

In this paper, a new method for detecting rotational landslides from two epochs of LiDAR data was proposed. The proposed method uses vector-based data as opposed to raster processing which was used in majority of the studies above. To test the proposed method, two epochs of LiDAR data were used. First epoch of the LiDAR data is real and the second epoch was simulated to include one or more rotational landslides.

\section{DATA DESCRIPTION}

The Ohio Department of Transportation (ODOT) acquired LiDAR data along the road MUS-666 (Zanesvellie, Columbus, Ohio, US) on Dec. 30, 2008 with $50 \mathrm{~cm}$ estimated resolution. Part of this data used in this study covers only the $8.30-8.80 \mathrm{~km}$ of the road MUS-666. Datum of the LiDAR data is NAD HARN State Plane Coordinate System for Ohio South Zone FIPS 3402 which was converted to meter. Average point spacing calculated for the data is $1.01 \mathrm{~m}$, with $9-15 \mathrm{~cm}$ estimated horizontal location accuracy and $15-25 \mathrm{~cm}$ vertical accuracy. The coordinates were obtained by the method of virtual reference station.

Last return of the LiDAR data was taken to create bare ground surface model for the purpose of landslide detection. Fig. 1 shows bare ground surface created by the LiDAR data. In the processing, all of the available points in the area were used, but only the area bounded by the rectangle in Fig. 1 was used to represent the results throughout the paper due to image clarity.

This paper focused on determination of rotational landslide area(s) by using two epochs of LiDAR data. Therefore, second epoch of LiDAR data was simulated from the first epoch LiDAR data so that the area included one or more rotational landslides. Different number and sizes of landslides were simulated making them more complex to be detected by the method. Detail of this strategy was given under 'simulation strategy' title in section 5 . 


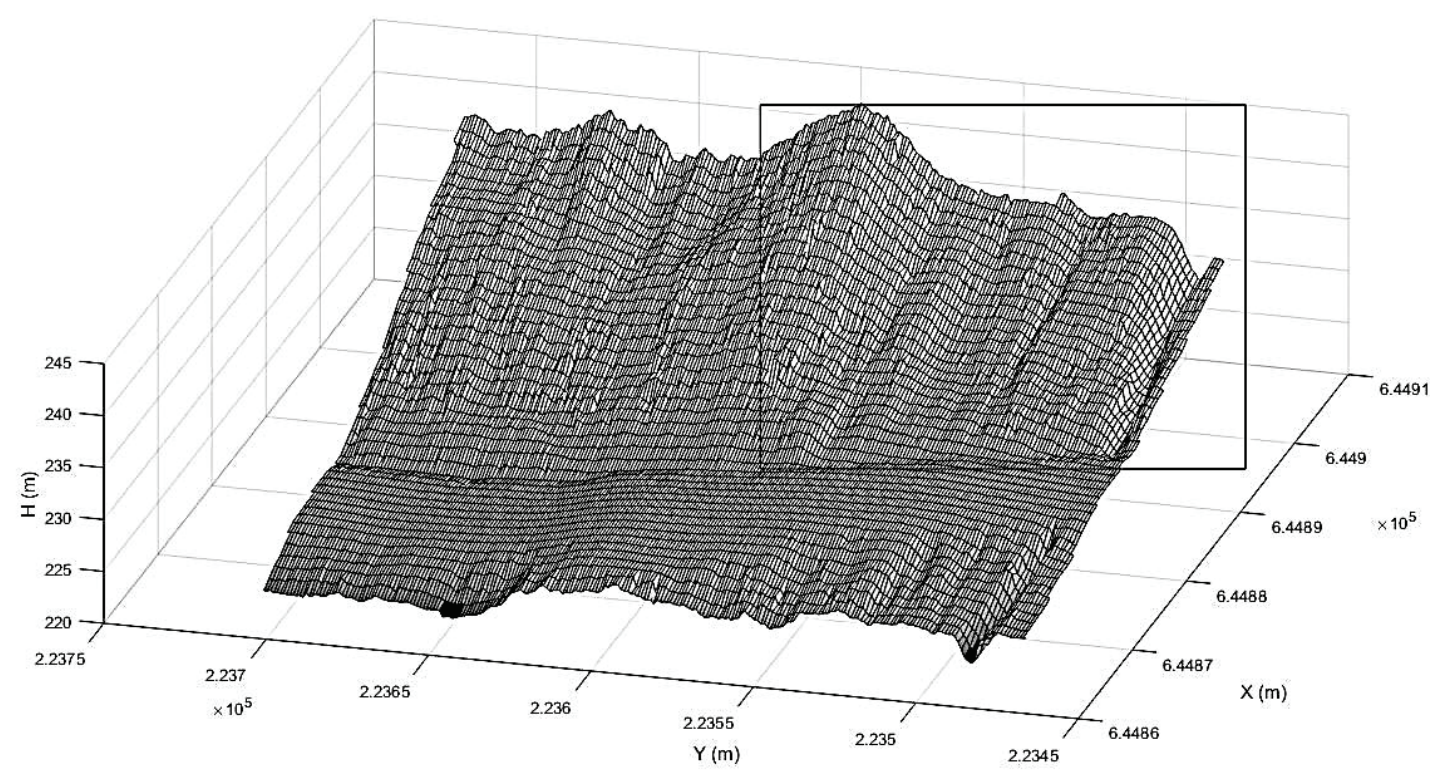

Figure 1 Bare ground surface mode

\section{SIMULATION}

The author in [12] classified landslides into various types, one of which is a rotational landslide. Suppose two epochs of LiDAR data represent two sets of XYH coordinates: one before and one after a landslide occurred for identical points. Then, for an individual rotational landslide, it can be inferred that the height differences of points between first and second epoch of XYH data approximately follow a sinewave form. Therefore, a sinewave with an amplitude (i.e. maximum deflection height) may be considered to represent a rotational landslide.

The magnitude of amplitude of the simulated landslide was determined as $10 \%$ of the distance from crown to toe to properly represent a real case. This is known as 2D landslide deposit aspect ratio, which was stated as ranging $0.02-0.15 \%$ [13]. In real case, height differences will not be zero outside the landslide area due to noise as opposed to perfect model. Therefore, white noise was added to simulated height differences with standard deviation, \pm 5 $\mathrm{cm}$. Since a landslide occurs along the steepest slope direction, sinewave effect was given in the differences heights along the steepest slope direction.

\section{PROPOSED SEGMENTATION METHOD}

The proposed segmentation method uses height differences of identical points. Therefore, both epochs of LiDAR data were gridded along the steepest slope direction with $30 \times 30 \mathrm{~cm}$ interval. Using 'nearest neighbors' approach, each grid mid point's height was interpolated for both epochs of LiDAR data. Then height difference of each identical point was calculated.

The proposed segmentation method was developed based on outlier detection procedure in [14]. In the procedure, absolute values of height differences between two epochs are taken as random variables. Next, the variables are normalized to obtain $Z$ scores (Eq. (1)). Then each $\mathrm{Z}$ score of each height difference is tested for whether it is outside the given level of significance (typically $\alpha=$ $0.05, Z=1.96$ ) or not. If the normalized height difference is bigger than $1.96 \sigma$ ( $\sigma=1$ for normalized variables), the difference is taken as outlier and its original value stored for segmentation, otherwise the difference is set to zero.

$Z_{i}=\frac{\left|d H_{i}\right|-\overline{\overline{d H}}}{s_{d H}}$,

where $d H_{i}$ represents the $i^{\text {th }}$ height difference, $\overline{\overline{d H}}$ represents the average value of absolute height differences and $s_{d H}$ is the standard deviation of the absolute height differences.

The area under investigation is profiled along the steepest slope direction using the gridded data before further tests were applied. The steepest slope direction is called 'horizontal' profile in this paper and the profile perpendicular to the horizontal profile is called 'vertical' one. The vertical profile is necessary to complete the procedure.

The procedure is applied to the height differences of points in each horizontal profile. For each profile, outlying successive points are grouped. Each point with successive next point with a zero height difference constitutes final point in the current group, and next group starts from next point with nonzero height difference after the last point with zero height difference. The groups formed by this method are deficient to form a sinewave due to point with zero height difference as being the separator for each group. On the other hand, a sinewave has three locations with zero values. Therefore, outlying height differences of each group are further tested whether they obey to a sinewave form or not. For this, a value for each successive group is calculated by counting the number of positive and negative height differences. The value is positive if the number of positive height differences is bigger than that of negative height differences in each group, or negative in the opposite case. Then two successive groups are joined if the values calculated for them are positive and negative respectively. This procedure is applied to each horizontal profile to complete the horizontal scanning. The steps of this process are depicted in Fig. 2 ( $a, b$ and c). In Fig.2, profile 83 is selected for the purpose of presentation. 
In Fig. 2a, height differences of identical points in profile 83 were presented as original values. After applying outlier test, corresponding points were given in Fig. 2b. Next, the result from further test to the points whether they obey sinewave form or not was given in Fig. 2c. It is noted that a real landslide diverges from the ideal sinewave. The above procedure includes those cases due to the fact that the number of positive and negative height differences does not have to follow the sinewave form. They indicate related point position with respect to positive or negative parts of a sinewave.

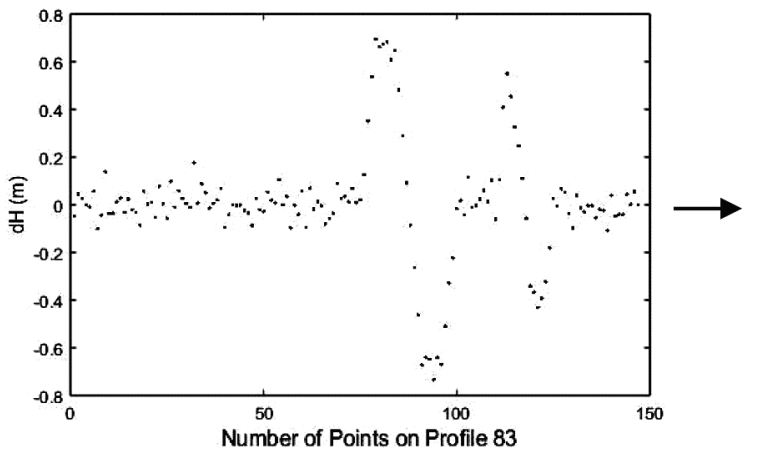

a)

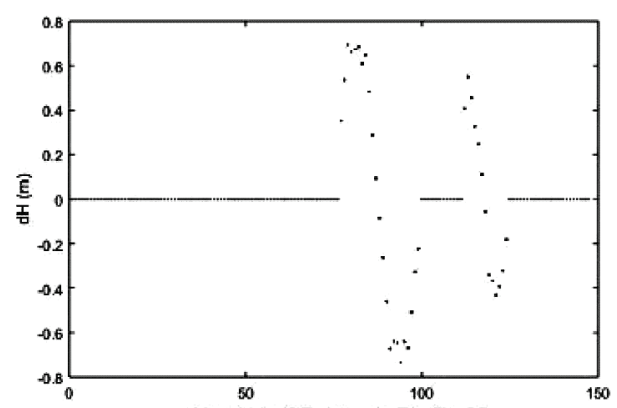

b)

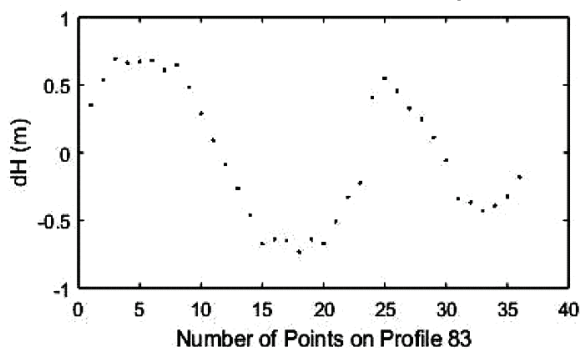

c)

Figure 2 Successive results of the procedure in profile 83 to obtain rotational landslides

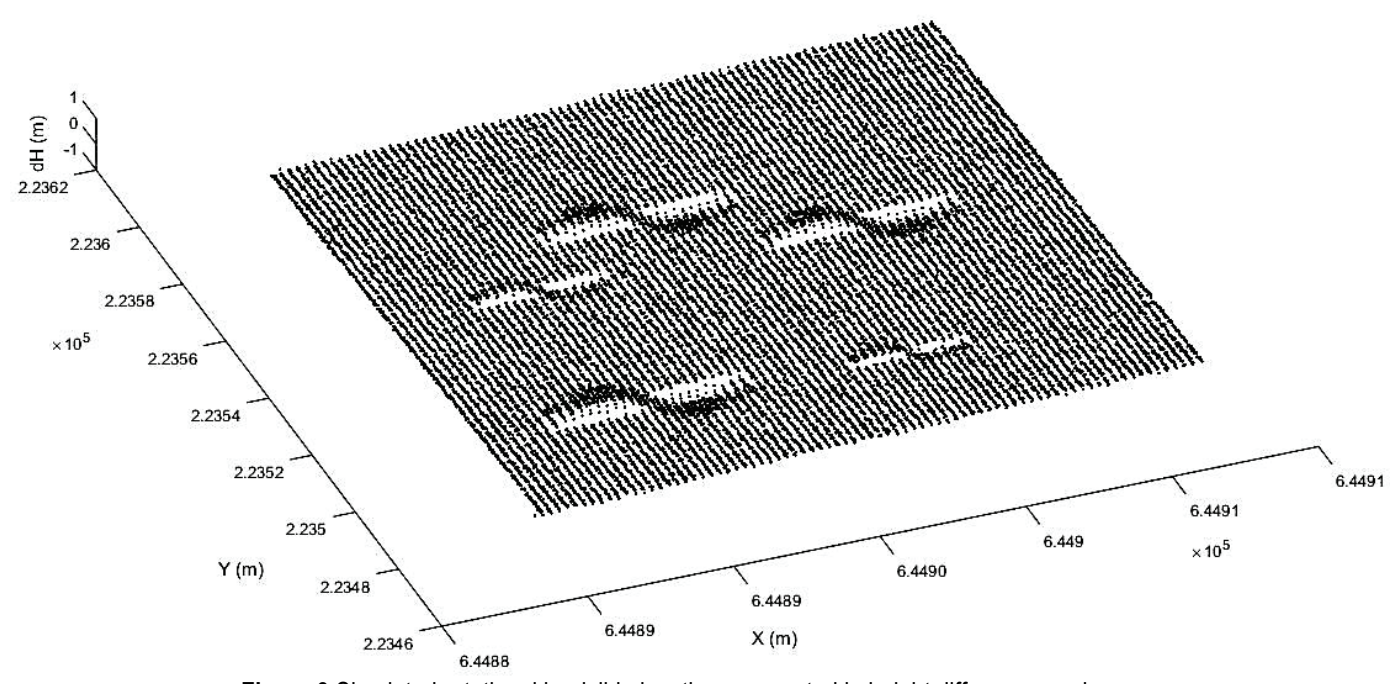

Figure 3 Simulated rotational landslide locations presented in height difference mode

Now segmentation of the area under investigation is completed along the steepest direction. Then, the same procedure except for further test for sinewave form is applied to explicitly determine the rotational landslide areas because in vertical scanning profiles do not form sinewave form.

\section{SIMULATION STRATEGY}

To test the proposed segmentation method properly, a simulation strategy was developed. Here, there are five rotational landslide areas chosen (Fig. 3).
In Fig. 3, first row at the bottom contains two landslides each of which has different amplitude (maximum deflection) and dimensions; the first one is $6 \times 7.5 \mathrm{~m}$ (i.e. width and length) with $0.75 \mathrm{~m}$ amplitude, the second one is $3 \times 4.5 \mathrm{~m}$ with $0.45 \mathrm{~m}$ amplitude. The second row also contains two rotational landslides, $3.6 \times 5.1 \mathrm{~m}$, with $0.5 \mathrm{~m}$ amplitude and $5.4 \times 7.2 \mathrm{~m}$ with $0.72 \mathrm{~m}$ amplitude respectively. Finally, the third row contains only one rotational landslide of $5.4 \times 7.2 \mathrm{~m}$ size with $0.72 \mathrm{~m}$ amplitude.

Since the segmentation procedure works the way in which the area is scanned in horizontal and vertical manner, it is questioned whether the method is capable of 
detecting each landslide separately if a large landslide shadows smaller one in the same profiles. Likewise, in the second row, the method is tested if the smaller one shadows the larger one. The second row is also considered to test the method if it works in vertical scanning. Finally, the third row is designed to overlap the gap between the first and the second rows of two landslides (Fig. 3).

\section{RESULTS AND DISCUSSIONS}

In Fig. 4, the results of horizontal scan by the proposed method are given. Here, it is clearly seen that horizontal grouping was successful in identifying the rotational landslides. Each rectangle in the figure depicts horizontal grouping. Here, group 1 and group 2 contain two landslides and group 3 contains one landslide. The aim, here, is to get each landslide separately. Therefore, vertical scanning is necessary for each horizontal group.

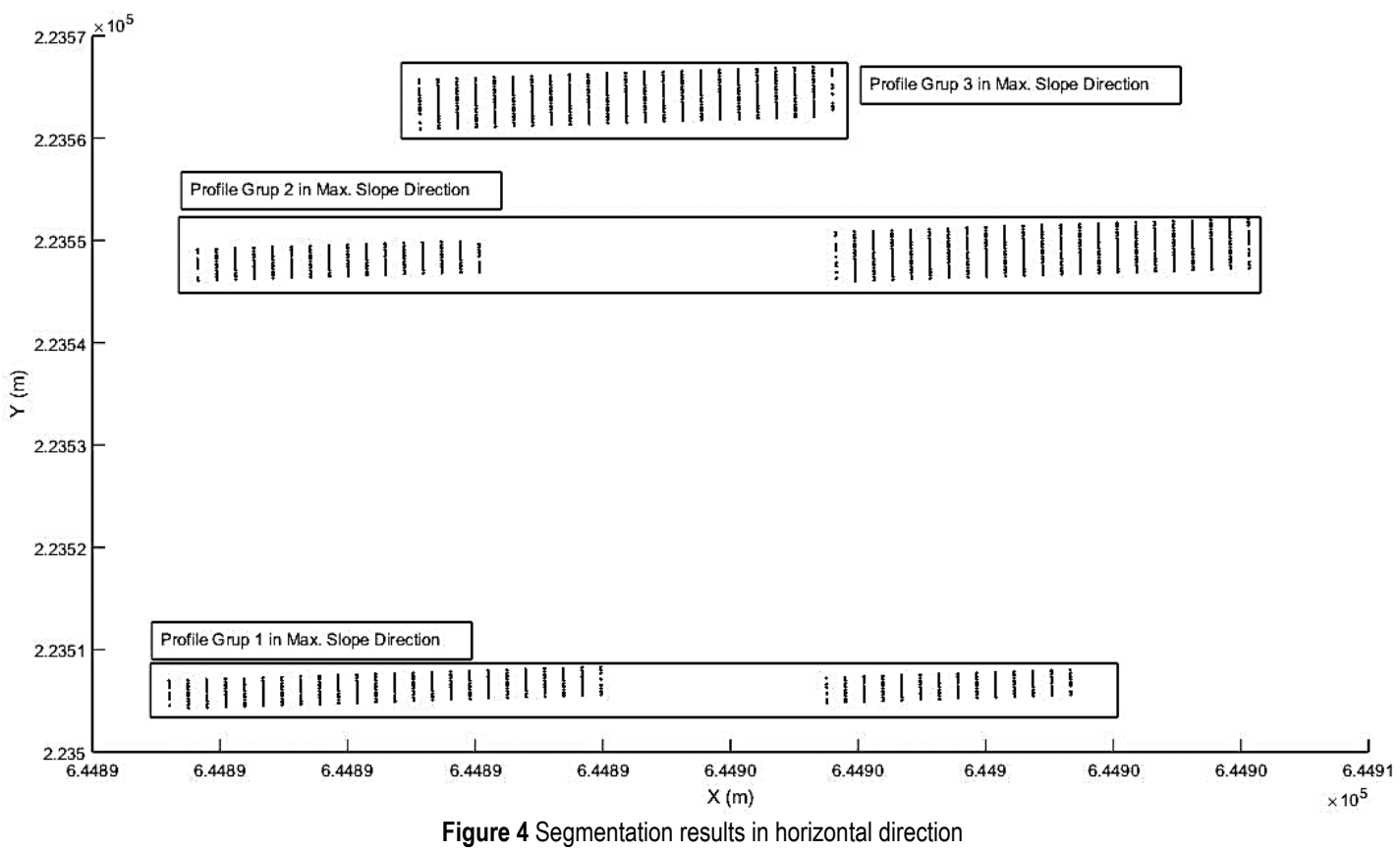

After applying the same procedure in vertical direction, each rotational landslide was fully determined (Fig. 5).

The procedure sorts the segmented groups with respect to their amplitude in descending order. The numbers on each segment represent the rotational landslides from the largest to the smallest. Each landslide was then kept in a separate data set. In Fig. 6 a, b, c, d and e, each segmented area was presented in $3 \mathrm{D}$.

The results of the method compared to the study done by [15] have some advantages. First, this method uses an approach of outlier detection, which makes it easy for real data to be applied. Second, $Z$ score (1.96) is highly common in engineering. Third, once this method is applied to data, the results require no further processing for a possible model to estimate the parameters of the particular landslide. However, the study done by [15] used low-pass filter with an arbitrary cut-off frequency applying Fourier Transformation to each profile which is identified by a sum of absolute values of height differences to segment the area. Therefore, it requires more than one application of the same procedure to the area identified by the segmentation.

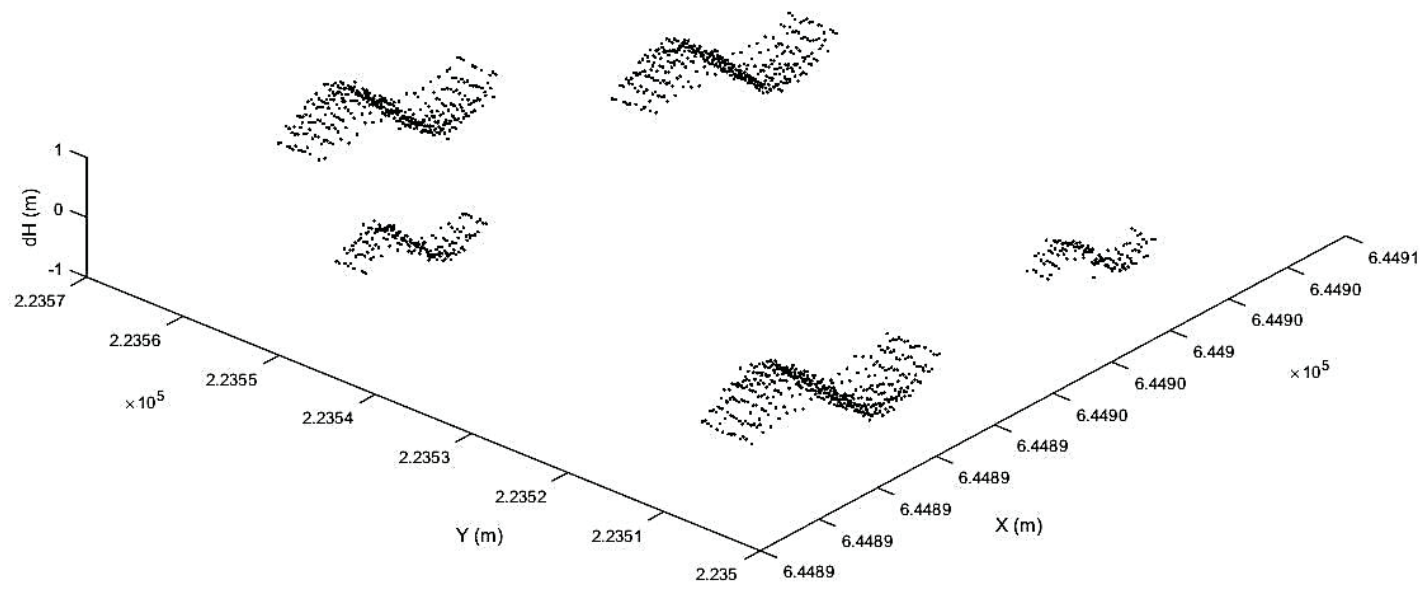

Figure 5 Final segmentation results in 3D 

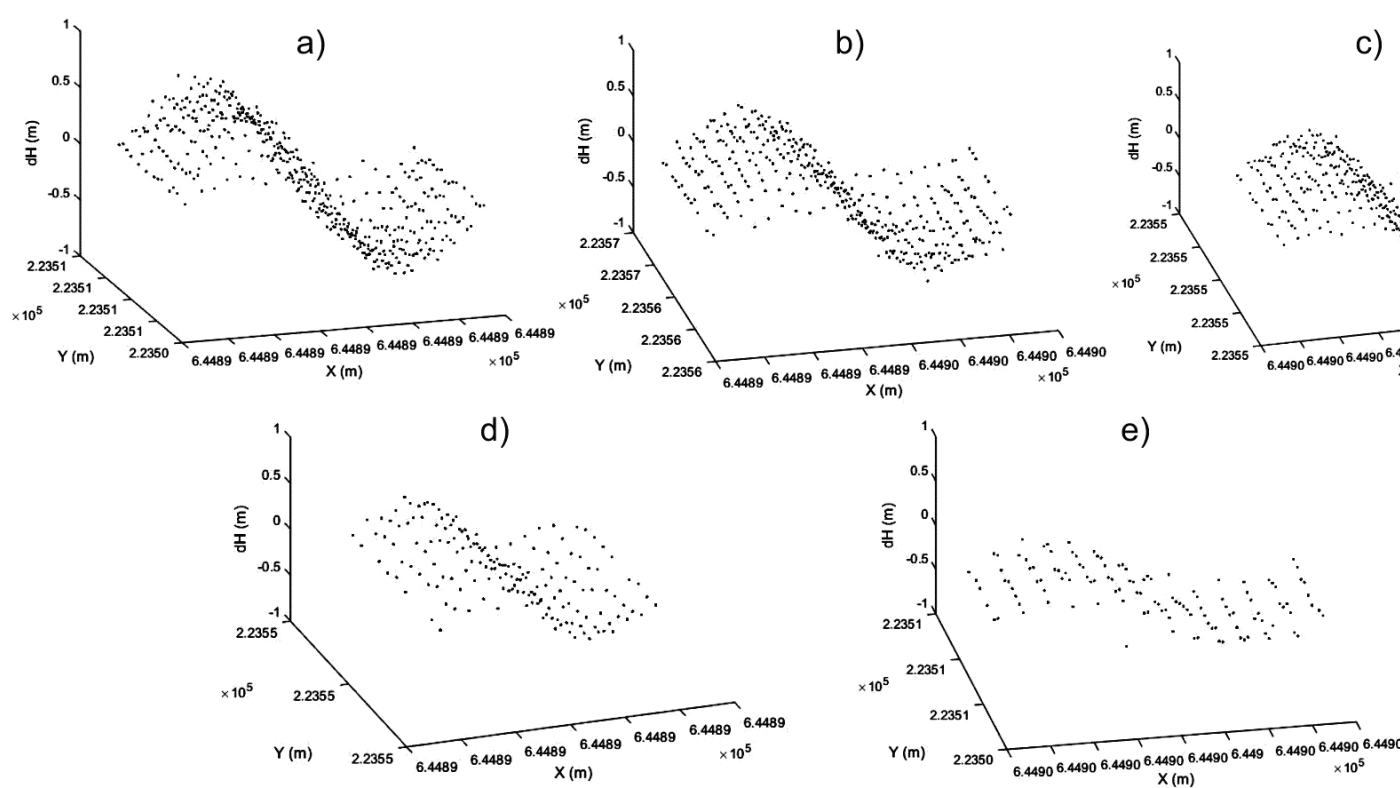

Figure 6 Segmented rotational landslides in separated form

Simulated and detected rotational landslides were tabulated in Tab. 1. Width and length of the simulated landslides were detected with exactly $0.6 \mathrm{~m}$ less in both width and length of the original size. This is due to the chosen significance level (0.05). If the significance level is chosen smaller than 0.05 value then the detected sizes will approach to its exact size while making it more complex in identifying the hypothesized model. The amplitude (maximum deflection) was not tabulated due to the fact that the original values of height differences of points were kept as they are.

Table 1 Simulated and detected rotational landslides

\begin{tabular}{|c|c|c|c|}
\hline \multirow{2}{*}{ Landslide No (Segment No) } & Simulated & Detected & Dorizontal size $(\mathrm{m})$ \\
\cline { 2 - 4 } & Horizontal size $(\mathrm{m})$ & $5.4 \times 6.9$ & $0.6 \times 0.6$ \\
\hline Landslide 1 (Seg_1) & $6.0 \times 7.5$ & $2.4 \times 3.9$ & $0.6 \times 0.6$ \\
\hline Landslide 2 (Seg_5) & $3.0 \times 4.5$ & $3.0 \times 4.5$ & $0.6 \times 0.6$ \\
\hline Landslide 3 (Seg_4) & $3.6 \times 5.1$ & $4.8 \times 6.6$ & $0.6 \times 0.6$ \\
\hline Landslide 4 (Seg_3) & $5.4 \times 7.2$ & $4.8 \times 6.6$ & $0.6 \times 0.6$ \\
\hline Landslide 5 (Seg_2) & $5.4 \times 7.2$ & & \multicolumn{1}{c}{0.6} \\
\hline
\end{tabular}

Applied outlier approach requires much higher number of undisturbed points than disturbed ones. Otherwise, outliers could not be properly detected.

This study uses vector data. Therefore, a particular window size for filtering is not necessary in this method. However, the steepest slope direction is the critical issue here because topography has variable slope directions. In this case, this approach is used as a preliminary detection stage with a general slope direction, which roughly identifies the disturbed areas. Then the approach is applied with a new steepest slope direction driven from the disturbed areas.

\section{CONCLUSIONS}

A new segmentation method was developed to detect rotational landslides using two epochs of LiDAR data. Developed segmentation method was based on outlier detection using $Z$ scores. For testing the method, a scenario was adopted to identify if the method capable of detecting landslides occurred in different locations that were shadowing each other with different sizes and amplitudes.

The method was found successful in detecting the five rotational landslides, each of which was stored in a separate file that contained only XYH coordinates which were ready for further modelling to estimate the parameters of rotational landslides.

The developed model relies on the steepest slope direction, which may be different in other part of the topography. If so, the proposed method may be used as a preliminary search. Then after determining disturbed areas, a new steepest slope direction can be calculated. Finally, the method can be used with new direction.

This method focused on a particular type of landslides i.e., rotational landslides. For other types, this procedure needs developing.

\section{Acknowledgments}

The author would like to special thank The Ohio Department of Transportation for providing data.

\section{REFERENCES}

[1] Shan, J. \& Toth, C. K. (Eds) (2009). Topographic Laser Ranging and Scanning principles and processing. CRC press Taylor and Francis group LLC, USA, $590 \mathrm{pp}$.

[2] McKean, J. \& Roering, J. (2004). Objective landslide detection and surface morphology mapping using highresolution airborne laser altimetry. Geomorphology, 57, 331351. https://doi.org/10.1016/S0169-555X(03)00164-8 
[3] Glenn, N. F., Streutker, D. R., Chadwick, D. J., Thackray, G. D., \& Dorsch, S. J. (2006). Analysis of LiDAR-derived topographic information for characterizing and differentiating landslide morphology and activity. Geomorphology, 73, 131-148. https://doi.org/10.1016/i.geomorph.2005.07.006

[4] Fernández, T., Jiménez, J., Fernández, P., El Hamdouni, R., Cardenal, F. J., Delgado, J., Irigaray, C., \& Chacón, J. (2008). Automatic Detection of Landslide Features with Remote Sensing Techniques in the Betic Cordilleras (Granada, Southern Spain). The International Archives of the Photogrammetry, Remote Sensing and Spatial Information Sciences, Vol. XXXVII, Part B8, Beijing.

[5] Burns, W. J., Jeffrey A. C., Kaya, E., \& Lina M. A. (2010). Analysis of Elevation Changes Detected from MultiTemporal LiDAR Surveys in Forested Landslide Terrain in Western Oregon. Environmental \& Engineering Geoscience, 16(4), 315-341. https://doi.org/10.2113/gseegeosci.16.4.315

[6] Jaboyedoff, M., Oppikofer, T., Abellan, A., Derron, M. H., Loye, A., Metzger, R., \& Pedrazzini, A. (2012). Use of LIDAR in landslide investigations: a review. Natural Hazards, 61(1), 5-28. https://doi.org/10.1007/s11069-010-9634-2

[7] Tarolli, P., Sofia, G., \& Dalla Fontana, G. (2012). Geomorphic features extraction from high-resolution topography: Landslide crowns and bank erosion. Natural Hazards, 61(1), 65-83. https://doi.org/10.1007/s11069-010-9695-2

[8] Khamsin, I. Zulkarnain, M., Razak, K. A., \& Rizal, S. (2014). Detection of tropical landslides using airborne LiDAR data and multi imagery: A case study in genting highland, Pahang. Earth and Environmental Science, 18, 012033. https://doi.org/10.1088/1755-1315/18/1/012033

[9] Chen, W., Li, X., Wang, Y., Chen, G., \& Liu, S. (2014). Forested landslide detection using LiDAR data and the random forest algorithm: A case study of the Three Gorges, China. Remote Sensing of Environment, 152, 291-301. https://doi.org/10.1016/j.rse.2014.07.004

[10] Tarolli, P. (2014). High-resolution topography for understanding Earth surface processes: Opportunities and challenges. Geomorphology, 216, 295-312. https://doi.org/10.1016/j.geomorph.2014.03.008

[11] Hussin, H. Y., Zumpano, V., Reichenbach, P., Sterlacchini, S., Micu, M., Westen, C. V., \& Bălteanu, D. (2016). Different landslide sampling strategies in a grid-based bivariate statistical susceptibility model. Geomorphology, 253, 508-523. https://doi.org/10.1016/j.geomorph.2015.10.030

[12] Varnes, D. J. (1978). Slope movement types and processes. In: Special Report 176: Landslides: Analysis and Control (Eds: Schuster, R. L. \& Krizek, R. J.). Transportation and Road Research Board, National Academy of Science, Washington D. C., 11-33

[13] Katz, O., Morgan, J. K., Aharonov, E., \& Dugan B. (2014). Controls on the size and geometry of landslides: Insights from discrete element numerical simulations. Geomorphology, 220, 104-113. https://doi.org/10.1016/j.geomorph.2014.05.021

[14] Cross, P. A. (1994). Advanced Least Squares Applied to Position Fixing. University of East London, School of Surveying Working Paper No: 6, London.

[15] Celik, C. T., Grejner-Brzezinska, D., \& Toth, C. (2013). Segmentation by Fourier Transformation for Landslide Detection from LIDAR Data. $13^{\text {th }}$ SGEM GeoConference on Informatics, Geoinformatics and Remote Sensing, SGEM2013 Conference Proceedings, June 16-22, Vol. 2, 397-404. https://doi.org/10.5593/SGEM2013/BB2.V2/S09.051

\section{Contact information:}

Cahit Tagi ÇELiK, Professor, PhD, MSc Niğde Omer Halisdemir Üniversitesi, Mühendislik Fakültesi, Harita Mühendisliği Bölümü, Niğde, 51245, Turkey

Tel: +903882252258, Fax: +902250112

E-mail: ctcelik@gmail.com 